\title{
Compositional and functional responses of bacterial community to titanium dioxide nanoparticles varied with soil heterogeneity and exposure duration
}

\author{
Yujia Zhai ${ }^{\mathrm{a}, 1}$, Lihua Chen ${ }^{\mathrm{b}, 1}$, Gang Liu ${ }^{\mathrm{b}, \mathrm{c}, *}$, Lan Song ${ }^{\mathrm{d}, * *}$, Daniel Arenas-Lago ${ }^{\mathrm{e}}$, Lingchao Kong $^{\mathrm{d}}$, \\ Willie Peijnenburg ${ }^{\mathrm{a}, \mathrm{f}}$, Martina G. Vijver ${ }^{\mathrm{a}}$ \\ anstitute of Environmental Sciences (CML), Leiden University, P.O. Box 9518, 2300 RA Leiden, the Netherlands \\ b Sanitary Engineering, Department of Water Management, Faculty of Civil Engineering and Geosciences, Delft University of Technology, P.0. Box 5048, 2600GA Delft, the Netherlands \\ ' Key Laboratory of Drinking Water Science and Technology, Research Centre for Eco-Environmental Sciences, Chinese Academy of Sciences, Beijing 100085, PR China

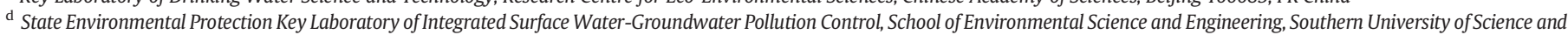 \\ Technology, Shenzhen 518055, PR China \\ e Department of Plant Biology and Soil Science, University of Vigo, As Lagoas, Marcosende, 36310 Vigo, Spain \\ ${ }^{\mathrm{f}}$ National Institute of Public Health and the Environment (RIVM), P.O. Box 1, Bilthoven, the Netherlands
}

\section{H I G H L I G H T S}

- Impacts of $\mathrm{TiO}_{2} \mathrm{NPs}$ on bacterial community varied with soil heterogeneity over time.

- No significant $\mathrm{TiO}_{2} \mathrm{NPs}$ impact was observed in clay-LOM and sandy soils.

- $\mathrm{TiO}_{2} \mathrm{NPs}$ significantly affected community composition and function in clayHOM soil.

- $\mathrm{TiO}_{2} \mathrm{NPs}$ suppressed Acidobacteria and Verrucomicrobia, and carbohydrates degradation.

- The influence of soil heterogeneity on the effects of $\mathrm{TiO}_{2} \mathrm{NPs}$ appeared transiently.

\section{A R T I C L E I N F O}

\section{Article history:}

Received 14 November 2020

Received in revised form 28 December 2020

Accepted 28 December 2020

Available online 4 February 2021

Editor: Jay Gan

\section{Keywords:}

Nanotoxicity

Soil properties

Organic matter
G R A P H I C A L A B S T R A C T

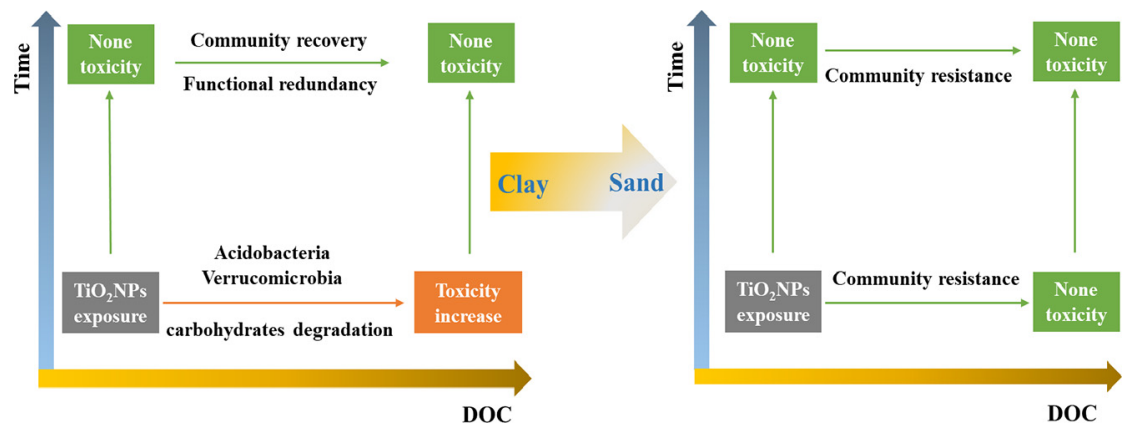

\begin{abstract}
A B S T R A C T
Titanium dioxide nanoparticles $\left(\mathrm{TiO}_{2} \mathrm{NPs}\right.$ ) are widely used as nano-agrochemicals. In this study we investigated the influence of soil heterogeneity on bacterial communities exposed to $\mathrm{TiO}_{2} \mathrm{NPs}$ over time. Clay and sandy soils with low- and high-organic matter contents were exposed to environmentally relevant concentration of $\mathrm{TiO}_{2} \mathrm{NPs}$ $(1 \mathrm{mg} / \mathrm{kg}$ ) and soil bacterial communities were sampled after short-term (15 days) and long-term exposure (60 days). After short-term $\mathrm{TiO}_{2}$ NPs exposure, significant effects regarding the enzyme activity, bacterial community structure and composition, and community functioning were observed in the clay soils with high organic matter (clay-HOM) but not in other soil groups. Response alterations were observed to taxa belonging to Acidobacteria and Verrucomicrobia, and functional pathways related to carbohydrates degradation. These results indicated that soil heterogeneity play more important roles in shaping the bacterial community in soil with low clay fraction and less organic matter, while $\mathrm{TiO}_{2} \mathrm{NPs}$ selection was the main driver in inducing the compositional and functional impacts on the soil bacterial community in the presence of clay soil with high organic matter
\end{abstract}

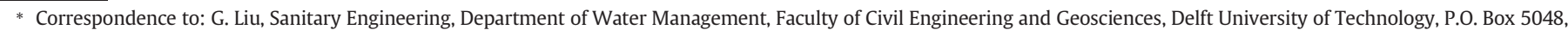
2600GA Delft, the Netherlands.

** Corresponding author.

E-mail addresses: gliu@rcees.ac.cn (G. Liu), songl@sustech.edu.cn (L. Song).

1 Equal contribution. 
Enzyme activity

Soil bacterial community content. As exposure time increased, the bacterial community recovered after a long-term exposure of 60 days,

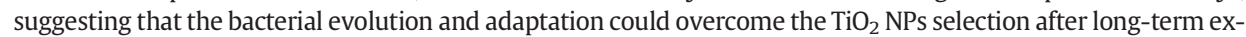
posure. Our results highlighted the importance of soil heterogeneity including clay fraction and organic matter and exposure duration in assessing the impact of nanoparticle on soil bacterial activity, community and function. By comprehensively evaluating the risks of nanoparticles on soil ecosystem and explicitly and explicitly include spatial and temporal variations, the benefit of nano-agrochemical products has the potential to be promoted in future applications.

(c) 2021 Elsevier B.V. All rights reserved.

\section{Introduction}

Titanium dioxide nanoparticles $\left(\mathrm{TiO}_{2} \mathrm{NPs}\right)$ are widely used in food additives, agricultural plant protection products, personal care and cosmetics, photocatalysts and UV protectors etc. (Tan et al., 2018). Throughout their life-cycle that ranges from production, transportation, application to disposal, $\mathrm{TiO}_{2} \mathrm{NPs}$ are inevitably released into the environment (Moll et al., 2017). It is estimated that approximately 760 tons of $\mathrm{TiO}_{2} \mathrm{NPs}$ per year are released into soils by application of sewage sludge (Gottschalk et al., 2009; Zhang et al., 2015). A recent study also illustrated that $\mathrm{TiO}_{2} \mathrm{NPs}$ could also be directly applied to soils through the use of agricultural products (Abdel Latef et al., 2018). With the increasing demands from the global market and their inevitable release into the environment, more research is needed to understand the fate and ecological risk assessment for $\mathrm{TiO}_{2}$ NPs ( $\mathrm{Li}$ et al., 2016a, 2016b; Rana et al., 2020).

The fate of $\mathrm{TiO}_{2}$ NPs in soil could be affected by soil properties, like e.g. texture, mineral and organic particles, $\mathrm{pH}$, and ionic strength (Simonin and Richaume, 2015). Metal oxide nanoparticles have been found in small soil aggregates rich in labile organic carbon, microbial biomass and clay (Tourinho et al., 2012). This indicates that these nanoparticles could interact with the clay fraction, organic matter components and microbes present (Antisari et al., 2013; Abbas et al., 2020). Clay components have been reported to facilitate the $\mathrm{TiO}_{2} \mathrm{NPs}$ transport (Cai et al., 2014). Moreover, studies have shown that high dissolved organic matter and clay contents promoted $\mathrm{TiO}_{2} \mathrm{NPs}$ dispersion in soil suspension, while high ionic strength, zeta potential, and $\mathrm{pH}$ inhibited $\mathrm{TiO}_{2}$ NPs stability (Fang et al., 2009). Therefore, organic materials such as organic waste and residues, manures, humic acid, have been added in the soil products containing metallic nanoparticles as a sustainable and remedial approach for controlling the mobility, bioavailability and toxicity of $\mathrm{TiO}_{2}$ NPs (Zhao et al., 2020). As organic matter could potentially influence the mobility and bioavailability of $\mathrm{TiO}_{2} \mathrm{NPs}$, it is critical to investigate the influence of soil heterogeneity i.e. texture and organic matter on the ecological risk of $\mathrm{TiO}_{2} \mathrm{NPs}$ in the soil ecosystem.

Soil bacterial community plays important roles in soil biogeochemical processes including organic carbon decomposition, nitrogen fixation, mineral recycling, plants nutrient acquisition, etc. (Falkowski et al., 2008). In terms of potential ecological risk of $\mathrm{TiO}_{2} \mathrm{NPs}$ in soil, previous studies have reported that $\mathrm{TiO}_{2} \mathrm{NPs}$ could alter the soil bacterial community composition and inhibit bacterial activity (Ge et al., 2012; Simonin et al., 2016; Zhai et al., 2019b). When released to complex soil matrices, $\mathrm{TiO}_{2} \mathrm{NPs}$ interact with the soil constituents like organic matter present in the clay fraction of a given soil. These interactions will influence the effect of $\mathrm{TiO}_{2} \mathrm{NPs}$ on soil bacterial community functioning over time (McKee and Filser, 2016). Soil bacterial respiration was for example, found to be negatively affected by short-term (7 days) $\mathrm{TiO}_{2}$ NPs exposure in clay soil with high organic matter content, whilst it was recovered after long-term incubation of 90 days (Simonin et al., 2015). However, many studies only provided insight from a single model of soil and did not take the heterogeneity of soils into consideration. It remains unknown how the soil bacterial community diversity is changed, which taxa are sensitive, and what soil bacterial mediated processes are disrupted in $\mathrm{TiO}_{2} \mathrm{NPs}$ exposure over time. Soil bacterial respiration was for example, found to be negatively affected by short-term (7 days) $\mathrm{TiO}_{2}$ NPs exposure in clay soil with high organic matter content, whilst it was recovered after long-term incubation of 90 days.

The objective of this study is to investigate the influences of soil heterogeneity on the bacterial communities exposed to $\mathrm{TiO}_{2}$ NPs over time. Soil samples were taken from clay and sandy soils with low- and highorganic matter content (LOM and HOM) exposed to $\mathrm{TiO}_{2}$ NPs for both short-term ( 1 day) and long-term (60 days) incubation. Soil enzyme activity, bacterial community diversity, composition and function were investigated to answer the following key questions: 1 ) how does the $\mathrm{TiO}_{2}$ NPs toxicity on bacterial community change across soil heterogeneity over time? 2) whether $\mathrm{TiO}_{2} \mathrm{NPs}$ exposure or soil heterogeneity determine the overall impact predominantly? 3) which featured taxa and function are sensitive to $\mathrm{TiO}_{2} \mathrm{NPs}$ exposure across the soil heterogeneity over time?

\section{Materials and methods}

\section{1. $\mathrm{TiO}_{2} \mathrm{NPS}$}

Titanium dioxide nanoparticles $\left(\mathrm{TiO}_{2} \mathrm{NPs}\right.$, anatase $(80 \%)$ and rutile (20\%) crystal structure, 99.5\% purity) were purchased from SigmaAldrich. The morphology of $\mathrm{TiO}_{2} \mathrm{NP}$ was characterized using Transmission electron microscopy (TEM) (JEOL 1010, IEOL Ltd., Japan), and the hydrodynamic size distribution was measured using dynamic light scattering (DLS) (Malvern, Instruments Ltd., UK). The physico-chemical properties of $\mathrm{TiO}_{2} \mathrm{NPs}$ were characterized in our previous study (Zhai et al., 2019a) and given in Fig. S1. In brief, $\mathrm{TiO}_{2}$ NPs are spherical powders, with pristine particle size of $25 \mathrm{~nm}$ and specific surface area of $35-65 \mathrm{~m}^{2} / \mathrm{g}$. The $\mathrm{TiO}_{2}$ NPs aggregated to larger aggregates with hydrodynamic diameter of $527 \pm 124 \mathrm{~nm}$ in soil extracts. The $\mathrm{TiO}_{2} \mathrm{NPs}$ powders were dispersed in MiliQ water and then sonicated at $4{ }^{\circ} \mathrm{C}$ at $38 \pm 10$ $\mathrm{KHz}$ for $16 \mathrm{~min}$ to make the stock suspension ( $25 \mathrm{mg} / \mathrm{L}$ ) following the Risk Assessment of Engineered Nanoparticles (ENPRA) protocol (Jacobsen et al., 2010).

\subsection{Soils}

Four different soils i.e. sandy or clay soils with low- or high-OM content were investigated in this study. Sandy soils were collected from the top $15 \mathrm{~cm}$ of a site dominated by deciduous trees with (high-OM content) and without fertilization (bark compost) (low-OM content) $\left(52^{\circ} 11^{\prime} 37.9^{\prime \prime} \mathrm{N} 4^{\circ} 30^{\prime} 16.4^{\prime \prime} \mathrm{E}\right.$, Warmond, The Netherlands). Clay soils were collected from an agricultural field (low-OM content) and under permanent pasture (high-OM content) $\left(52^{\circ} 12^{\prime} 28.2^{\prime \prime} \mathrm{N} 4^{\circ} 30^{\prime} 32.1^{\prime \prime} \mathrm{E}\right.$, Warmond, The Netherlands). The collected soils were sieved with $2 \mathrm{~mm}$ sieve and stored at $4{ }^{\circ} \mathrm{C}$. The detailed characteristics of the soil samples are listed in Table $\mathrm{S} 1$.

\subsection{Experimental design}

Prior to the experiment, soils were pre-incubated for one week at $20{ }^{\circ} \mathrm{C}$. $\mathrm{TiO}_{2}$-NPs stock suspensions was added drop by drop using a pipet into $60 \mathrm{~g}$ of each soil (equivalent to $50 \mathrm{~g}$ dry weight) and thoroughly mixed manually for $5 \mathrm{~min}$. An exposure concentrations of 
$1 \mathrm{mg} / \mathrm{kg} \mathrm{TiO} 2$ NPs was achieved, which represented a realistic environmental concentration (Sun et al., 2014). The same amount of sterilized water without $\mathrm{TiO}_{2}$ NPs was added into the control soils. Soil microcosms were incubated at $20^{\circ} \mathrm{C}$ for 15 and 60 day representing shortand long-term exposure (Zhai et al., 2019a). In total 48 microcosms with triplicate per treatment were prepared ( 4 soils $\times 2$ concentrations of $\mathrm{TiO}_{2} \mathrm{NPs}$ (i.e. 0 and $1 \mathrm{mg} / \mathrm{kg}$ ) $\times 2$ sampling times $\times 3$ replicates). Soil water content was maintained at $24 \%$ during the incubation using sterile water. In each microcosm, ten grams of soil were subsampled by the end of each incubation time and immediately used for bacterial community analysis.

\subsection{Enzyme activity}

The enzyme activity of the tested soils was measured by the dehydrogenase activity according to the 2-[4-iodophenyl]-3-[4-nitrophenyl]-5-phenyltetrazolium chloride (INT) assay (Von Mersi and Schinner, 1991). In brief, each soil sample was mixed with Tris Buffer (Tris(hydroxymethyl)aminomethane, $1 \mathrm{M}$, Sigma-Aldrich) and substrate solution (2( $p$-iodophenyl)-3-( $p$-nitrophenyl)-5-phenyl tetrazolium chloride (iodonitrotetrazolium chloride (INT), $10 \mathrm{mM}$, SigmaAldrich), and then incubated in the dark for $2 \mathrm{~h}$ at $40^{\circ} \mathrm{C}$. After the incubation, the soil was extracted by a solution consisting of $\mathrm{N}, \mathrm{N}$ dimethylformamide/ethanol in a 1:1 ratio, in the dark for $30 \mathrm{~min}$ at $20{ }^{\circ} \mathrm{C}$ to extract the developed iodonitrotetrazolium formazan (INTF). The developed INTF was determined color metrically at $\lambda=464 \mathrm{~nm}$ (UV-1800, Shimadzu, Kyoto, Japan). The dehydrogenase activity was expressed as mg INTF/g dry soil $/ 2 \mathrm{~h}$.

\subsection{DNA extraction and Illumina Miseq sequencing}

Soil DNA was extracted from $0.3 \mathrm{~g}$ of each soil sample using Qiagen DNeasy PowerSoil Kit (Hilden, Germany). DNA quality control checks were performed by downstream sequencing. PCR amplification was performed using a universal bacterial primer set (515F: 5'-GTGCCAGC MGCCGCGGTAA-3' and 909R: 5'-CCCGTCAATTCMTTTRAGT-3') targeting the variable V4-V5 regions of bacterial 16S rRNA genes (Liu et al., 2017). Paired-end sequencing was performed by BaseClear (Leiden, the Netherlands) using the $2 \times 300 \mathrm{bp}$ Illumina Miseq platform (Illumina, Inc., San Diego, CA, USA). The sequences have been deposited into the NCBI database with project number: PRJNA660920, and the sample information is provided in Table S2.
Data obtained through Illumina sequencing were processed using the Quantitative Insights Into Microbial Ecology (QIIME2) pipeline (Bolyen et al., 2019). In brief, the QIIME 2 pipeline includes sequence quality control, feature table construction, phylogenetic tree generation, diversity analysis and taxonomic analysis. Sequences quality control was performed using the software package DADA2 for modeling and correcting for Illumina-sequenced amplicon errors. Qualified sequences were processed to construct the FeatureTable which contained frequencies of each unique sequence in each sample and FeatureData which maps feature identifiers in the FeatureTable to the sequences they represent. The FeatureTable was collapsed at the genus level (i.e. level 6 of the Greengenes taxonomy) The phylogenetic tree was built using the q2-phylogeny plugin. Community diversity was analyzed through the q2-diversity plugin, which supports computing alpha and beta diversity metrics. The sampling depth was rarefied at 5500 to remove the heterogeneity. The rarefaction curve is shown in Fig. S2. The taxonomic assignment to the sequences in the FeatureData was conducted using the q2-feature-classifier plugin. Phylogenetic investigation of communities by reconstruction of unobserved states (PICRUSt) was used to further translate the 16S rRNA gene amplicon data into predicted metagenomes to predict the soil bacterial community functional profile (Langille et al., 2013). MetaCyc pathway was used to annotate the predicted metagenomes. PICRUSt was processed using PICRUSt2 pipeline in QIIME2 to generate FeatureTable which contained frequencies of MetaCyc pathway abundance in each sample.

\subsection{Statistical analysis}

All bacterial responses i.e. enzyme activity, community diversity, structure, composition and functional profile were analyzed among the different treatments (clay-LOM, clay-HOM, sand-LOM and sandHOM) at the selected time points (short- and long-term). One-way analysis of variance (ANOVA) and post hoc Tukey HSD were performed to test the influence of soil properties and exposure time on the effect of $\mathrm{TiO}_{2}$ NPs on soil enzyme activity (Fig. S3). Significance testing on the community alpha diversity comparisons across the different treatments was performed using the QIIME2 diversity alpha-group-significance plugin. To test whether bacterial communities differed among treatments, community dissimilarities based on both taxonomic and functional composition were illustrated using principal coordinates analysis (PCoA) based on the weighted UniFrac distance matrices. The significance of community dissimilarity was further tested using Permutational multivariate analysis of variance (PERMANOVA). To

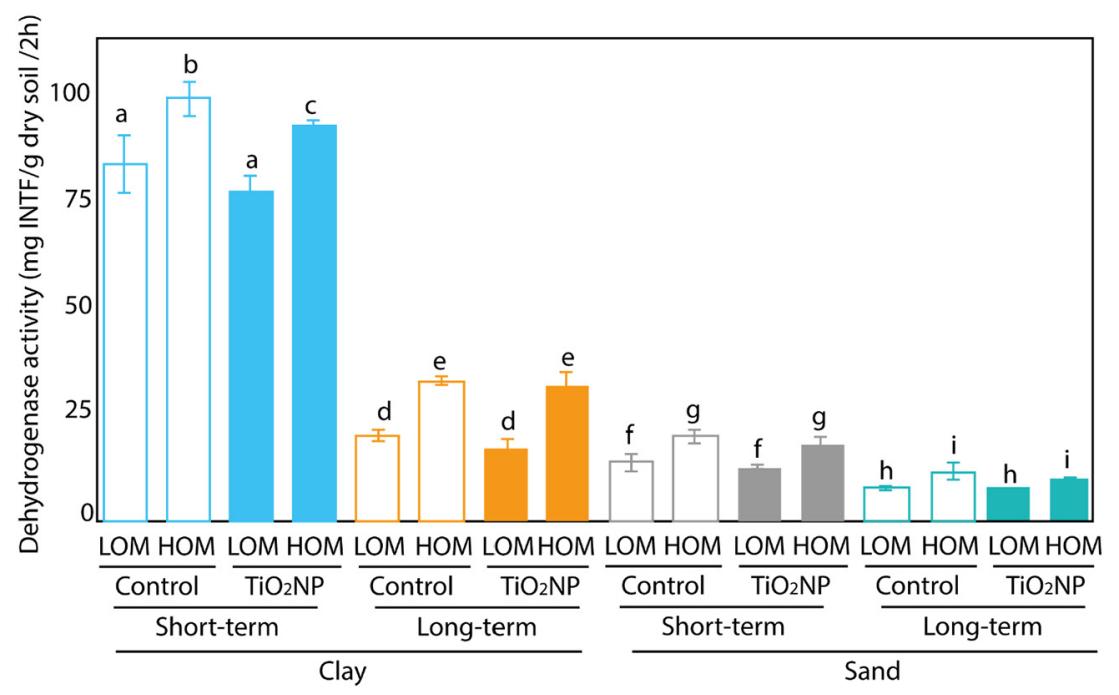

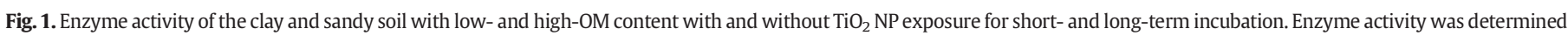

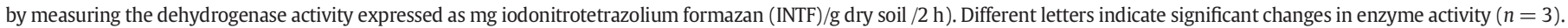


investigate the changes in taxonomic as well as functional composition of the soil bacterial community, analysis of composition of microbiomes (ANCOM) was applied to identify features (i.e. feature taxa and feature pathways) that are differentially abundant between the low- and high$\mathrm{OM}$ content clay and sandy soils with and without $\mathrm{TiO}_{2} \mathrm{NPs}$ exposure at each time point. Correlation between feature taxa and functional pathways were calculated using pairwise Spearman's rank processed in $R$ v3.6.1. (psych package). Networks with coefficient at 0.7 and statistically significant $(p<0.05)$ were visualized using Gephy v0.9.1.

\section{Results}

3.1. Influence of soil heterogeneity on soil enzyme activity in response to $\mathrm{TiO}_{2}$ NPs exposure over time

The impact of $\mathrm{TiO}_{2}$ NPs on the bacterial dehydrogenase activity of the tested soils is shown in Fig. 1. In short-term incubation, the dehydrogenase activity in the clay-HOM and sand-HOM soils increased from $83.2 \pm 7.8$ to $98.2 \pm 3.7$ and from $13.4 \pm 0.3$ to $20.2 \pm 1.6 \mathrm{mg}$ INTF $/ \mathrm{kg}$ soil $/ 2 \mathrm{~h}$, respectively. The addition of $\mathrm{TiO}_{2}$ NPs induced no significant difference in either clay-LOM, sand-LOM or sand-HOM soils. However, the dehydrogenase activity in the clay-HOM soil significantly decreased $(p<0.05)$ from $98.2 \pm 3.7$ to $91.3 \pm 1.4 \mathrm{mg}$ INTF $/ \mathrm{kg}$ soil $/ 2 \mathrm{~h}$, indicating that the bacterial enzyme activity was significantly affected by $\mathrm{TiO}_{2} \mathrm{NPs}$ exposure in clay soil with high organic matter. Moreover, $\mathrm{TiO}_{2}$ NPs exposure reduced the enzyme activity by $7.9 \pm 5.3 \%$ in the clay-LOM and $11.8 \pm 6.5 \%$ in sand-LOM soils, suggesting that the impact of $\mathrm{TiO}_{2} \mathrm{NPs}$ exposure in sand induced more serious impact on the bacterial enzyme activity compared with clay. After long-term exposure, the dehydrogenase activity in the clay-HOM and sand-HOM soils increased from $19.2 \pm 1.3$ to $31.5 \pm 1.2$ and from $7.8 \pm 0.2$ to $10.6 \pm 2.1 \mathrm{mg}$ INTF/ $\mathrm{kg}$ soil/2 h, respectively. The addition of $\mathrm{TiO}_{2} \mathrm{NPs}$ induced no significant difference in the clay and sandy soils, no matter whether the soil contained a low- or long-OM content. These results indicated that the

\section{(A) Phylogenetic diversity}

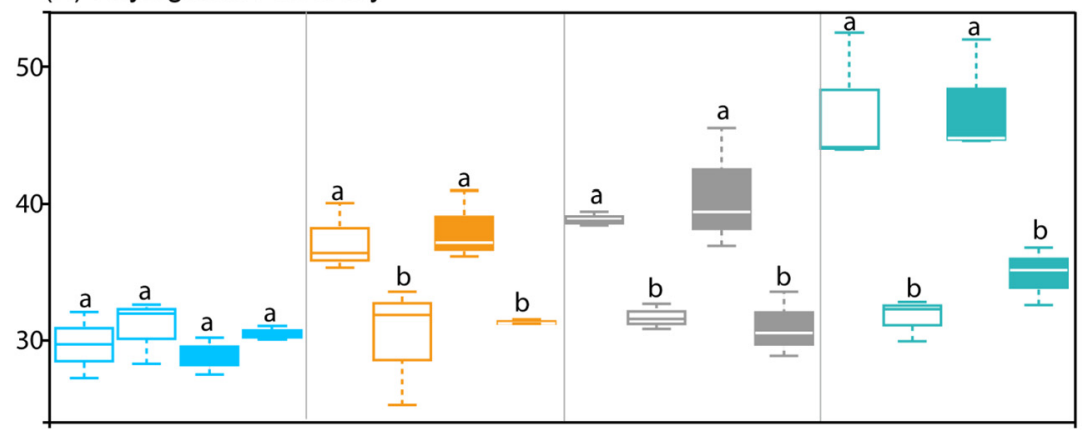

(B) Shannon diversity

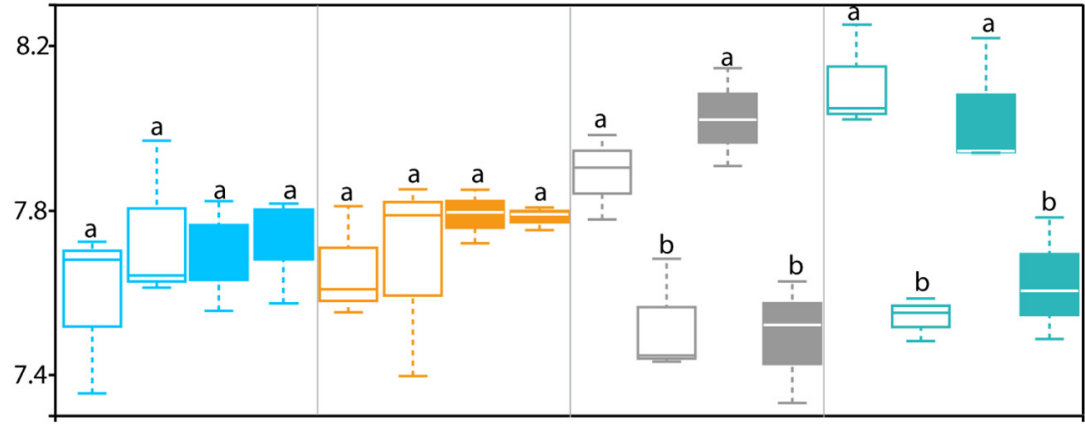

(C) Evenness

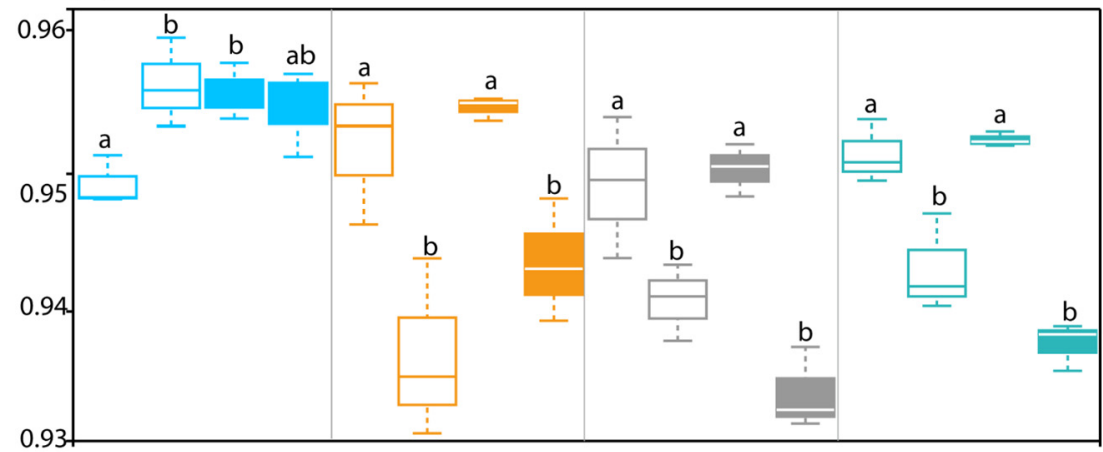

LOM HOM LOM HOM LOM HOM LOM HOM LOM HOM LOM HOM LOM HOM LOM HOM

\begin{tabular}{|c|c|c|c|c|c|c|c|}
\hline Control & $\mathrm{TiO}_{2} \mathrm{NP}$ & Control & $\mathrm{TiO}_{2} \mathrm{NP}$ & Control & $\mathrm{TiO}_{2} \mathrm{NP}$ & Control & $\mathrm{TiO}_{2} \mathrm{NP}$ \\
\hline \multicolumn{2}{|c|}{ Short-term } & \multicolumn{2}{|c|}{ Long-term } & \multicolumn{2}{|c|}{ Short-term } & \multicolumn{2}{|c|}{ Long-term } \\
\hline
\end{tabular}

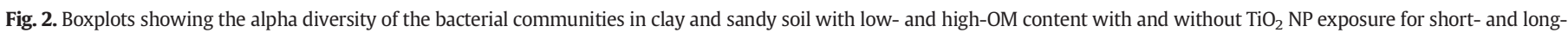
term incubation. (A) Phylogenetic diversity. (B) Shannon diversity. (C) Evenness. Different letters indicate significant changes in alpha diversity indexes ( $\mathrm{n}=3$ ). 
high-OM content promoted the soil enzyme activity, while $\mathrm{TiO}_{2} \mathrm{NPs}$ exposure transiently inhibited this promotion in the clay-HOM treatment transiently.

\subsection{Influence of soil heterogeneity on the bacterial community in response to $\mathrm{TiO}_{2} \mathrm{NPs}$ exposure over time}

\subsubsection{Responses of bacterial community diversity}

In total, 386,568 sequences obtained from 48 samples, were assigned as 11,787 OTUs. The rarefaction curve becomes flat after reaching 2000 sequences (Fig. S2), indicating sufficient sequence depth of this study. The impact of $\mathrm{TiO}_{2} \mathrm{NPs}$ on the community alpha diversity (i.e. phylogenetic diversity, Shannon diversity and evenness) of the clay and sandy soils with different OM content is given in Fig. 2. For clay soil in short-term incubation, a high-OM content promoted the community alpha diversity indexes, and a significant increase in community evenness was observed in high-OM treatment $(p<0.05)$. However, the increase in community alpha diversity which was induced by a high-OM content was inhibited after $\mathrm{TiO}_{2} \mathrm{NPs}$ addition, where no significant difference in alpha diversity between the low- and high$\mathrm{OM}$ content was observed in the presence of $\mathrm{TiO}_{2} \mathrm{NPs}$. After long-term incubation, community phylogenetic diversity and evenness were significantly decreased in high-OM treatment $(p<0.05)$, regardless of $\mathrm{TiO}_{2}$ NPs exposure. The sand community phylogenetic diversity, Shannon diversity and evenness significantly decreased as OM-content increased in both short- and long-term incubation, and these indexes were not affected by the $\mathrm{TiO}_{2} \mathrm{NPs}$ exposure. These results suggested that short-term exposure of $\mathrm{TiO}_{2} \mathrm{NPs}$ reduced community alpha diversity especially in the clay-HOM soil.

The impact of $\mathrm{TiO}_{2}$ NPs on the community beta diversity (based on weighted UniFrac distance matrices) of the clay and sandy soils with different $\mathrm{OM}$ content is given in Fig. 3. The results of significance testing of community dissimilarity are summarized in Table S3. The environmental factors of exposure time (short- and long-term), soil texture (clay and sand) and OM content (low and high) significantly explain the variation in community dissimilarity. Although the $\mathrm{TiO}_{2} \mathrm{NP}$ treatment did not significantly alter the bacterial communities in all the tested soils, a clear separation between the control and $\mathrm{TiO}_{2} \mathrm{NP}$ treatment was observed in the clay-HOM soil in short-term $\mathrm{TiO}_{2} \mathrm{NP}$ exposure. As exposure time increased, the bacterial communities of the control and $\mathrm{TiO}_{2} \mathrm{NP}$ treatments were separated in the clay soil with both low- and high-OM content. This indicated that $\mathrm{TiO}_{2} \mathrm{NP}$ exposure affected the community beta diversity. However, the bacterial communities of the control and $\mathrm{TiO}_{2} \mathrm{NP}$ treatments grouped together in all the sandy soils, regardless of OM-content and incubation time. This indicated that the community beta diversity was not affected by the addition of $\mathrm{TiO}_{2} \mathrm{NPs}$ in all the sandy soils.

\subsubsection{Responses of bacterial community taxonomic composition}

The above reported community similarity results showed that the impact of $\mathrm{TiO}_{2} \mathrm{NP}$ on the clay and sandy soil bacterial communities changed along with the OM-content in both short- and long-term exposure. We further investigated the community composition in clay and sandy soil with low- and high-OM content in the presence and absence of $\mathrm{TiO}_{2} \mathrm{NP}$ exposure in short- and long-term incubation. As shown in Fig. S4, the soil bacterial community was predominated by Proteobacteria (28.6\%-51.2\%), Actinobacteria (2.7\%-35.3\%) and Acidobacteria (5.6\%-16.8\%). To further investigate the community compositional changes among different treatments, a differential abundance test was performed at genus level to identify features that are differentially abundant across soil sample groups (Fig. 4). The parameters of significance testing for each featured taxa are given in Table S4-11. For the control clay soil in short-term exposure, the most abundant featured taxa in low-OM content were genera belonging to Proteobacteria, Acidobacteria and Actinobacteria. The increased OM content promoted the diversity of featured taxa, with genera belonging to Chloroflexi, Verrucomicrobia and Gemmatimonadetes appearing in the bacterial community with high-OM content. After $\mathrm{TiO}_{2} \mathrm{NP}$ addition, the featured taxa in the clay soil with low-OM content still belonged to Proteobacteria, Acidobacteria and Actinobacteria, and Verrucomicrobia. However, the $\mathrm{TiO}_{2} \mathrm{NPs}$ addition reduced the diversity of featured taxa in the high-OM content soil, with most featured taxa belonging to Proteobacteria. As incubation time increased, the decreased diversity of featured taxa induced by $\mathrm{TiO}_{2} \mathrm{NPs}$ treatment disappeared. A high OM content promoted diversity of the differentially abundant featured taxa, whatever $\mathrm{TiO}_{2} \mathrm{NPs}$ treatment. This indicated that as incubation time increased, the impact of $\mathrm{TiO}_{2} \mathrm{NPs}$ decreased. For the sandy soil in short-term incubation, increasing OM-content promoted the diversity of featured taxa, regardless of $\mathrm{TiO}_{2} \mathrm{NPs}$ treatment. As incubation time increased, the promoted diversity of featured taxa by OM-content disappeared in both control and $\mathrm{TiO}_{2} \mathrm{NPs}$ treatment. This indicated that OM-content and exposure time were the main drivers for the featured taxa and $\mathrm{TiO}_{2} \mathrm{NP}$ had little effect on the soil bacterial community in sandy soil.

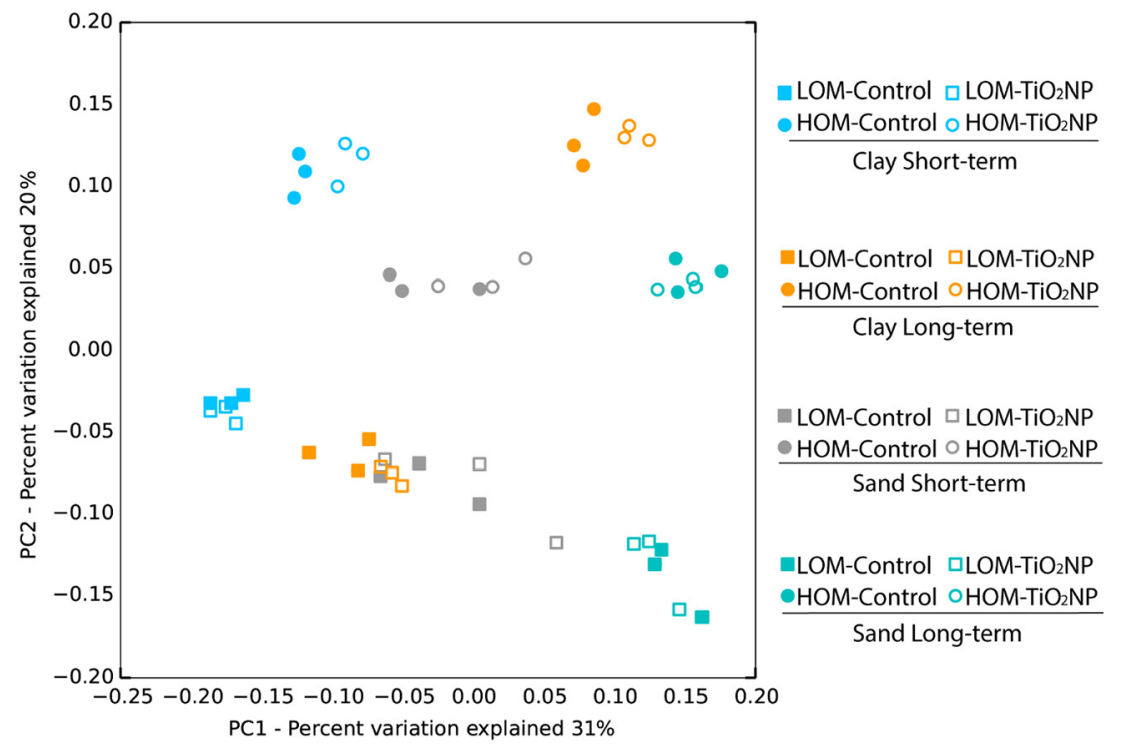

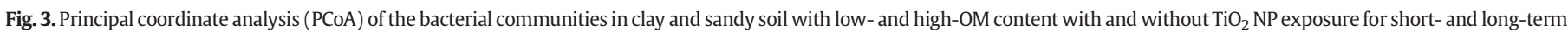
incubation based on taxonomic composition. 

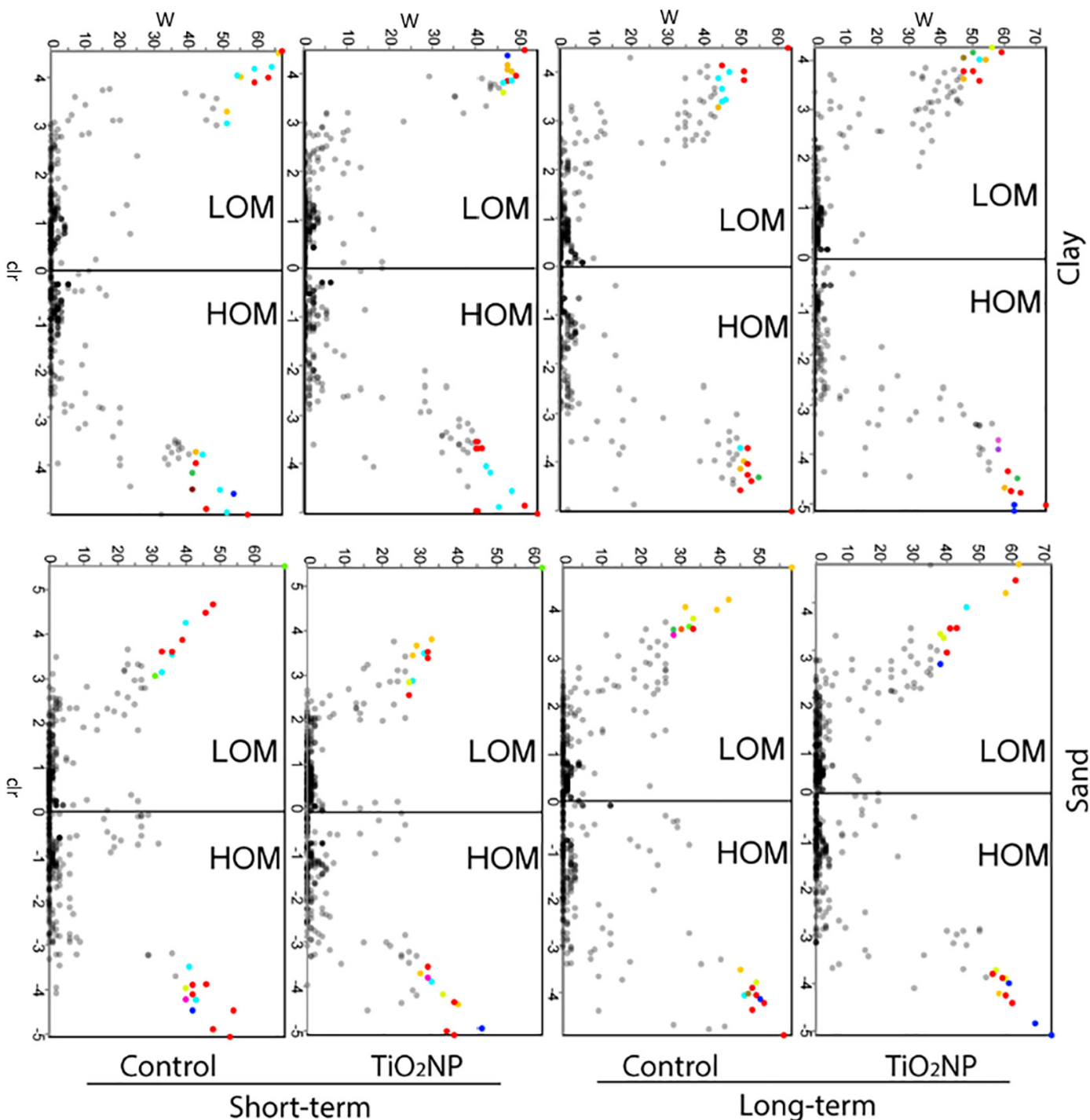

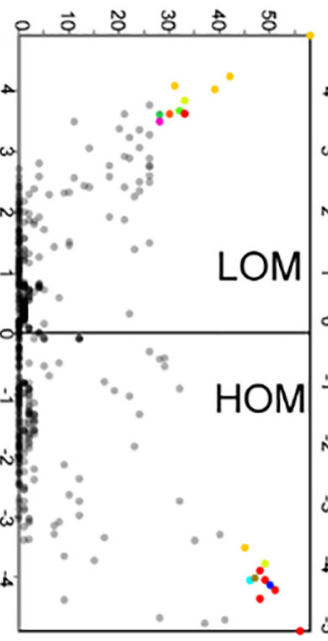

Control

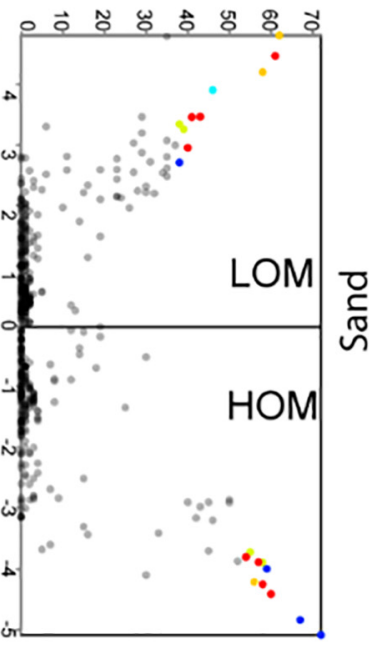
- Proteobacteria
Acidobacteria
Actinobacteria
- Chloroflexi
- Chlamydiae

Long-term

\section{- Planctomycetes \\ - Armatimonadetes \\ - Patescibacteria \\ - Firmicutes}

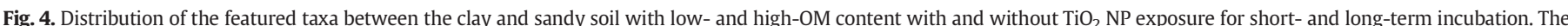

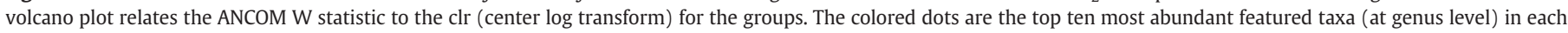
treatment that belong to the phyla in the legend.

3.3. Influence of soil heterogeneity on bacterial community function in response to $\mathrm{TiO}_{2} \mathrm{NPs}$ exposure over time

\subsubsection{Responses of the bacterial community functional profile}

The impact of $\mathrm{TiO}_{2} \mathrm{NPs}$ on the microbial community functional profile of the clay and sandy soils with different OM content is given in Fig. S5. The results of significance testing of community dissimilarity are summarized in Table S12. The exposure time (short- and long-term), soil texture (clay and sand) and OM content (low and high) significantly explain the variation in community dissimilarity. There was no significant effect of $\mathrm{TiO}_{2} \mathrm{NPs}$ on the microbial community functional profile of the tested soils. However, separation between the control and the $\mathrm{TiO}_{2} \mathrm{NPs}$ treatment was observed in clay soil in short-term exposure. After long-term exposure, the separation between the control and the $\mathrm{TiO}_{2} \mathrm{NPs}$ treatment had disappeared in the clay soil. For the sandy soil, there was no separation in community functional profile between the control and the $\mathrm{TiO}_{2}$ NPs treatments regardless of OM content and exposure time.

\subsubsection{Responses of bacterial community functional composition}

To understand the impact of $\mathrm{TiO}_{2} \mathrm{NP}$ on the functional composition of the soil bacterial community among the different treatments, featured pathways were further identified across soil sample groups (Fig. S6). For the control clay soil in short-term exposure, diverse feature pathways were identified in both low- and high-OM content soils (i.e. amino acid biosynthesis, fermentation, carbohydrate biosynthesis and carbohydrate degradation), indicating that the functional composition 
of clay soil was altered by the OM content. However, the discrepancy disappeared after $\mathrm{TiO}_{2} \mathrm{NP}$ treatment, with only one featured pathway identified in the low-OM-content clay (carbohydrate degradation). This suggested that the addition of $\mathrm{TiO}_{2} \mathrm{NP}$ reduced the divergence induced by OM. After long-term exposure, there were no featured pathways identified in either control or $\mathrm{TiO}_{2} \mathrm{NP}$ treated clay soil, indicating a decreased effect of $\mathrm{TiO}_{2} \mathrm{NP}$ along with time. For the sandy soil, no featured pathway was identified in either the low- and high-OM content treatment in either short- or long-term exposure, and regardless of $\mathrm{TiO}_{2} \mathrm{NPs}$ addition. This indicated that the functional composition of the sand bacterial community was not affected by $\mathrm{TiO}_{2} \mathrm{NP}$ treatment.

\subsubsection{Co-occurrence between featured taxa and function}

MetaCyc pathway was further used to annotate the predicted metagenomes, and the co-occurrence patterns of the identified feature taxa and pathways in all samples were visualized by co-network analysis (only data are shown with correlation coefficient $r>0.9$ and significant $p<0.01$, Fig. 5). The annotations for the functional pathways are listed in Table S13. In total 71/139 positive correlations were established among featured taxa (22) and pathways (84). Notably, the observed declined diversity of feature taxa in clay soil after short-term $\mathrm{TiO}_{2} \mathrm{NPs}$ treatment, i.e. Acidobacteriales (Acidobacteria) and Opitutus (Verrucomicrobia) are positively correlated with pathways related to carbohydrates degradation and biosynthesis e.g. P269 (Starch biosynthesis), P102 (Purine nucleobases degradation). This indicated that the short-term $\mathrm{TiO}_{2} \mathrm{NPs}$ treatment affected the functional pathways related with carbohydrates degradation and biosynthesis in clay soil bacterial community.

\section{Discussion}

4.1. Toxicity of $\mathrm{TiO}_{2} \mathrm{NPs}$ on soil bacterial communities varied as the soil heterogeneity over time

The toxicity of $\mathrm{TiO}_{2}$ NPs on soil bacterial communities was found to varied as the soil heterogeneity. In short-term exposure of $\mathrm{TiO}_{2} \mathrm{NPs}$, we observed that the enzyme activity in sand was lower than the

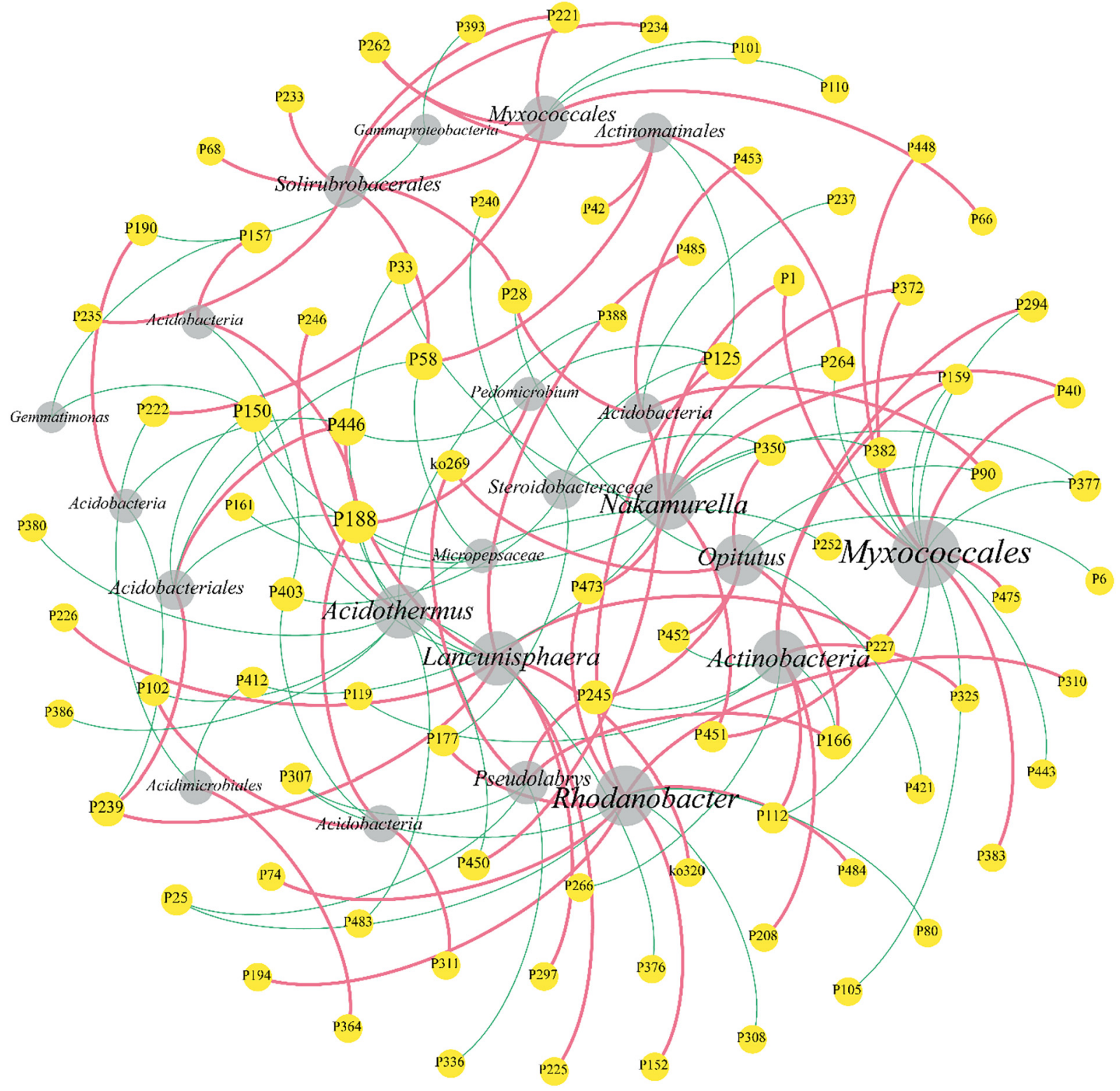

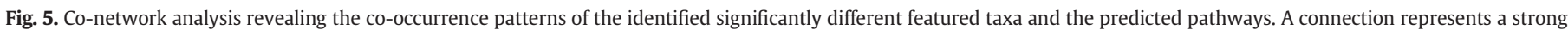

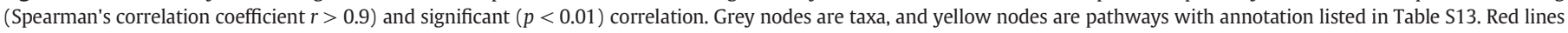

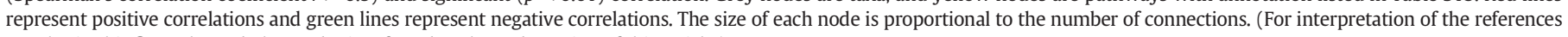
to color in this figure legend, the reader is referred to the web version of this article.) 
activity in the clay soils (Fig. 1 ). A significant effect of $\mathrm{TiO}_{2} \mathrm{NPs}$ bacterial dehydrogenase activity has previously been reported (Li et al., 2014). In this study, the limited effects of $\mathrm{TiO}_{2} \mathrm{NPs}$ on the clay soil could be explained by the role of clay particles on $\mathrm{TiO}_{2}$ NPs stability and mobility. Electrostatic interactions were found to mainly drive the affinity of $\mathrm{TiO}_{2}$ NPs to clay particles (Labille et al., 2015), and the interaction of clay particles and $\mathrm{TiO}_{2}$ NPs could affect the $\mathrm{TiO}_{2}$ NPs distribution between the solid soil matrix and the porewater and decreasing the mobility of the particles in the soil (Fang et al., 2009). Moreover, we also observed that the ionic strength in clay soils was higher than in the case of sandy soils (Table S1). A high ionic strength favors the attachment of nanoparticles to the clay matrix due to the electrical double layer compression (Chen et al., 2011). The formed clay- $\mathrm{TiO}_{2} \mathrm{NPs}$ hetero-aggregates could affect the transport of $\mathrm{TiO}_{2} \mathrm{NPs}$, and may lower the impacts of $\mathrm{TiO}_{2} \mathrm{NPs}$ on the soil bacterial activity (Labille et al., 2015; Simonin et al., 2015).

In addition, significantly inhibition of enzyme activity only occurred in clay-HOM soil (Fig. 1). Decrease in community alpha diversity was also observed in short-term exposure of $\mathrm{TiO}_{2} \mathrm{NPs}$ in clay-HOM soil (Fig. 2). Moreover, although not significant, clear bacterial community separation between the control and $\mathrm{TiO}_{2} \mathrm{NPs}$ treatment was observed in the clay-HOM soil (Fig. 3). The absence of effects in the clay soil with low OM soil suggested that soil clay fraction was not the only factor influencing $\mathrm{TiO}_{2} \mathrm{NPs}$ toxicity, and the $\mathrm{OM}$ content also influenced the effect of $\mathrm{TiO}_{2} \mathrm{NPs}$. The enhanced effect of $\mathrm{TiO}_{2} \mathrm{NPs}$ by OM content was also observed in soil bacteria (Simonin et al., 2015), aquatic protozoan (Gupta et al., 2017), and water flea (Fan et al., 2016). Natural organic matter could promote $\mathrm{TiO}_{2}$ NPs dispersion due to the combined effect of increased electrostatic and steric repulsions between $\mathrm{TiO}_{2} \mathrm{NPs}$ particles (Thio et al., 2011). After interacting with OM, large $\mathrm{TiO}_{2}$ NPs aggregates could be broken into small particles which may facilitate $\mathrm{TiO}_{2} \mathrm{NPs}$ exposure and bioavailability (Wang et al., 2016).

Moreover, the $\mathrm{TiO}_{2}$ NPs effects on bacterial community crossed the tested soil samples were observed to change along with exposure time. In short-term exposure we observed clear community separation (based on taxonomic composition) between the control and $\mathrm{TiO}_{2} \mathrm{NPs}$ treatment only in the clay-HOM samples. After long-term exposure, separation between the control and $\mathrm{TiO}_{2} \mathrm{NPs}$ treatment also appeared in the clay soil with low-OM content. This indicated that the disruption by $\mathrm{TiO}_{2} \mathrm{NPs}$ of the bacterial community structure was enhanced by exposure time. Previous studies have also found that after 60-90 days exposure of $\mathrm{TiO}_{2} \mathrm{NPs}$, the soil bacterial community structure modified and community diversity decreased, suggesting that aged $\mathrm{TiO}_{2} \mathrm{NPs}$ can affect soil bacterial community even at low concentrations and after a long exposure (Ge et al., 2011; Simonin et al., 2016). However, the inhibited enzyme activity and the community functional profile dissimilarity between $\mathrm{TiO}_{2}$ NPs treatment and control observed in the clayHOM samples, appeared transitory and were no longer observed after long-term exposure. This indicated that after long-term exposure compositional alterations occur but they do not yet necessarily reflect a biologically significant impact on the functioning of the soil bacterial community (Zhai et al., 2019a). A similar functional redundancy was also observed in a periphytic community in long-term exposure to $\mathrm{TiO}_{2}$ NPs (Liu et al., 2019). These results indicate that the duration of exposure is another key factor for assessing $\mathrm{TiO}_{2} \mathrm{NPs}$ ecotoxicity. The organic matter-NPs aggregates and the aging of NPs potentially reduce their bioavailability and mobility in soil, and the microbial adaptation or evolutionary process may take place in long-term to cope with the external stress (Wang et al., 2016).

4.2. Compositional and functional responses of soil bacterial community to $\mathrm{TiO}_{2}$ NPs in soils varying with clay and OM components

We further identified the sensitive taxa and pathways in response to $\mathrm{TiO}_{2}$ NPs exposure in the tested soils based on the taxonomic and functional composition. The increased OM content was found to promote the diversity of featured taxa, with genera belonging to Chloroflexi, Verrucomicrobia and Gemmatimonadetes appearing in the bacterial community with high-OM content. Studies have reported that Chloroflexi were related with aromatic compound degradation (Colatriano et al., 2018), Verrucomicrobia were candidates for polysaccharide-degrading bacterioplankton (Cardman et al., 2014), and Gemmatimonadetes were replete of genes of carbohydrate hydrolysis (Li et al., 2016a). However, in the presence of $\mathrm{TiO}_{2}$ NPs the promotion of community diversity in the clay soil was inhibited (Fig. 4). This indicated that $\mathrm{TiO}_{2} \mathrm{NPs}$ altered the community composition related to the clay fraction. $\mathrm{TiO}_{2} \mathrm{NPs}$ have been found to decrease bacterial diversity in silty-clay soil (Simonin et al., 2016). Moreover, we found that in absence of $\mathrm{TiO}_{2}$ NPs, bacterial genera belonging to Acidobacteria and Verrucomicrobia were the featured taxa in the clay-HOM soil, while these featured taxa disappeared in the same soil upon $\mathrm{TiO}_{2} \mathrm{NPs}$ addition. The exposure to $\mathrm{TiO}_{2}$ NPs promoted genera belonging to Proteobacteria as the most featured taxa. Similar shifts in bacterial community composition were reported in soils amended with silver nanoparticles, with significant decreases in the relative abundance of Acidobacteria and Verrucomicrobia and an increase in Proteobacteria (McGee et al., 2017). Similar to the antibacterial properties of silver nanoparticles, studies have shown that $\mathrm{TiO}_{2} \mathrm{NPs}$ exposure to bacteria could induce cell membrane damage, causing oxidative stress and producing reactive oxygen species (ROS) (Simon-Deckers et al., 2009). On the other hand, after being incorporated into the cell, nanoparticles could induce the generation of ROS, which increased the membrane permeability and facilitated the horizontal transfer of the antibacterial resistant genes ( $\mathrm{Su}$ et al., 2019). The OM in the clay soil might facilitate the stability and toxicity to the soil bacterial community, inhibiting the sensitive taxa and altering the community composition. However, the decrease in the diversity of the featured taxa by $\mathrm{TiO}_{2}$ NPs exposure appeared transiently. After long-term exposure, high-OM content no longer promoted the diversity of featured taxa, and the reduced diversity of featured taxa induced by $\mathrm{TiO}_{2}$ NPs addition disappeared. In our previous study, we also observed that the impact of $\mathrm{TiO}_{2} \mathrm{NPs}$ at the environmentally relevant concentration $(1 \mathrm{mg} / \mathrm{kg}$ ) on soil bacterial composition appeared transiently (Zhai et al., 2019a). As exposure time increased, the physicochemical properties of $\mathrm{TiO}_{2} \mathrm{NPs}$ in soil could change along with time due to e.g. aging, aggregation, interaction with clay minerals and organic matter, which reduced the bioavailability of $\mathrm{TiO}_{2}$ NPs (Tourinho et al., 2012). The adaption of the soil bacterial community could also contribute to the community recovery after long-term $\mathrm{TiO}_{2} \mathrm{NPs}$ exposure $(\mathrm{Wu}$ et al., 2018).

In addition to the bacterial community taxonomic composition, we also analyzed the functional composition in response to $\mathrm{TiO}_{2} \mathrm{NPs}$ exposure in the tested soils based on the MetaCyc pathways abundance (Figs. 5 and S6). Alterations in functional composition were only observed in clay soils in short-term exposure, with more featured pathways identified in the clay-HOM soil-related to carbohydrates degradation and biosynthesis. However, the presence of $\mathrm{TiO}_{2} \mathrm{NPs}$ disrupted the promotion by $\mathrm{OM}$, with no featured pathway identified in the high-OM content. Combining the results of taxonomic composition, the short-term exposure of $\mathrm{TiO}_{2} \mathrm{NPs}$ could inhibit the positive effect of OM on soil bacterial community by reducing the diversity of featured taxa and pathways related to carbohydrates degradation and biosynthesis. Nevertheless, the effect of $\mathrm{TiO}_{2} \mathrm{NPs}$ on the functional composition disappeared after long-term exposure. Similar bacterial community functioning recovery was also found in soil, stream water, and sediments exposed to titanium dioxide, silver, and copper nanoparticles (Colman et al., 2012; Sheng et al., 2015; Moore et al., 2016; Zhai et al., 2019a). When the soil bacterial community was exposed to $\mathrm{TiO}_{2} \mathrm{NPs}$, the sensitive taxa were not able to survive, which induced bacterial community compositional alterations. However, the resistant taxa may have an overproduction of extracellular polymeric substances that could form aggregates with $\mathrm{TiO}_{2} \mathrm{NPs}$ to reduce the toxicity (Joshi et al., 2012). Moreover, the loss of the susceptible taxa functioning 
could be compensated for by the promotion of survival taxa sharing the similar functioning (Zhai et al., 2019a). The soil bacterial community may experience evolutionary adaptation after long-term exposure to $\mathrm{TiO}_{2}$ NPs and remains sustainable functioning (Liu et al., 2019). Considering that in this study we did not observe the effect of long-term $\mathrm{TiO}_{2}$ NPs exposure on the diversity of the featured taxa, the highly diverse species could compensate for the partial disruption of community functioning regulated by certain taxa (Rosenfeld, 2002; Strickland et al., 2009). This resulted in a functionally redundant soil bacterial community that the community functioning could recover after long-term incubation (Allison and Martiny, 2008).

Combining the responses of bacterial enzyme activity, community taxonomic composition and community functional profile, significant impacts of $\mathrm{TiO}_{2}$ NPs exposure was observed in the clay-HOM soil. These results further indicated that $\mathrm{TiO}_{2} \mathrm{NPs}$ selection was the main driver in inducing the compositional and functional impacts on the soil bacterial community in the presence of clay with high organic matter content. Our previous study identified various patterns of bacterial community dynamics due to $\mathrm{TiO}_{2}$ NPs selection, depending on the bacterial tolerance (Zhai et al., 2019b). In this study, $\mathrm{TiO}_{2} \mathrm{NPs}$ exposure was found to suppress bacterial genera belonging to Acidobacteria and Verrucomicrobia while promote taxa belonging to Proteobacteria. The resistant taxa could establish persistence by means of detoxification enzymes, acclimation, and horizontal transfer of resistant genes (Ernst et al., 2016), while the less tolerant taxa could cope with the stress which caused damage (Griffiths and Philippot, 2013). In addition, the impact of $\mathrm{TiO}_{2}$ NPs was not significant in sand and clay-LOM soil, suggesting that the soil heterogeneity play more important roles in shaping the bacterial community soil with low clay fraction and less organic matter. Nevertheless, the alterations in bacterial community induced by $\mathrm{TiO}_{2} \mathrm{NPs}$ was found to be transient. After long-term exposure, the natural evolution and adaptation of soil bacterial community overcome the $\mathrm{TiO}_{2}$ NPs selection, with no significance observed before and after $\mathrm{TiO}_{2} \mathrm{NPs}$ addition. Although we did not find a significant effect of $\mathrm{TiO}_{2}$ NPs on the soil bacterial community functioning in long-term exposure, the disruption of the community taxonomic composition indicated that the bacterial stability decreased, which potentially makes the community more vulnerable to the next external stress. In our previous work we reported that exposure to multiple doses of $\mathrm{TiO}_{2} \mathrm{NPs}$ induces more severe effects on soil bacterial communities compared to exposure to a dose. Given that $\mathrm{TiO}_{2}$ NPs are released via waste discharge or repetitively applied as agrochemicals into soil, the fate and behavior of the nanoparticles in soil matrix as well as the accumulated impacts of multiple exposures on the soil microbial communities need to be assessed. In view of the increasing application of nanoparticles-containing products and the inevitable higher release into soil environment, future investigations into the spatial and temporal impacts are urgently needed for safe development of nano-products.

\section{Conclusion}

In conclusion, the impact of $\mathrm{TiO}_{2}$ NPs on soil bacterial communities depended on the soil heterogeneity and exposure time. Clay fraction and organic matter content were found to influence the effect of $\mathrm{TiO}_{2}$ NPs on soil bacterial community. Bacterial enzyme activity inhibition, community compositional and functional disruption were observed when $\mathrm{TiO}_{2}$ NPs exposed in clay soil with high organic matter content, where featured taxa belonging to Acidobacteria and Verrucomicrobia and functional pathways related to carbohydrates degradation were suppressed. No significant impacts of $\mathrm{TiO}_{2} \mathrm{NPs}$ was observed in the clay soil with low organic matter content and all the sandy soils. These results suggested that $\mathrm{TiO}_{2}$ NPs selection was the main driver in inducing the compositional and functional impacts on the soil bacterial community in the presence of clay soil with high organic matter content, and soil heterogeneity play more important roles in shaping the bacterial community in soil with low clay fraction and less organic matter. In addition, the influence of soil heterogeneity on the effect of $\mathrm{TiO}_{2}$ NPs appeared transiently. The bacterial evolution and adaptation overcome the $\mathrm{TiO}_{2} \mathrm{NPs}$ selection after long-term exposure, and the bacterial community varied with the soil heterogeneity. These findings suggested that soil heterogeneity such as soil texture, organic matter content, and exposure duration play important roles in determining $\mathrm{TiO}_{2} \mathrm{NPs}$ impacts on soil bacterial community. Given the large numbers of nano-fertilizers, additives, and organic amendments being added to agricultural systems, future research regarding with the timedependent interactions between soil heterogeneity and nanotoxicity is needed to better understand the fate and ecotoxicological impacts of nanoparticles-containing products on the soil ecosystem.

\section{CRediT authorship contribution statement}

Yujia Zhai: Conceptualization, Investigation, Methodology, Data curation, Formal analysis, Writing - original draft, Writing - review \& editing. Lihua Chen: Conceptualization, Investigation, Methodology, Data curation, Formal analysis, Writing - original draft, Writing - review \& editing. Gang Liu: Supervision, Validation, Visualization, Funding acquisition, Project administration, Writing - original draft, Writing - review \& editing. Lan Song: Supervision, Validation, Visualization, Funding acquisition, Project administration, Writing - original draft, Writing - review \& editing. Daniel Arenas-Lago: Data curation, Methodology, Writing - review \& editing. Lingchao Kong: Visualization, Formal analysis. Willie Peijnenburg: Supervision, Validation, Funding acquisition, Project administration, Writing - review \& editing. Martina G. Vijver: Supervision, Validation, Funding acquisition, Project administration, Writing - review \& editing.

\section{Declaration of competing interest}

The authors declare that they have no known competing financial interests or personal relationships that could have appeared to influence the work reported in this paper.

\section{Acknowledgements}

The authors would like to acknowledge the support from the National Key R\&D Program of China (2018YFE0204100), National Natural Science Foundation of China for International Cooperation and Exchange (51820105011) and the European Union's Horizon 2020 Research and Innovation Programme under grant agreement number 760813 "PATROLS". Additional supported was provided by the Leading Talents of Guangdong Province Program awarded to Chunmiao Zheng (No. 475 2016LJ06N469). D. Arenas-Lago thanks for his grant ED481D 2019/007 to Xunta de Galicia.

\section{Appendix A. Supplementary data}

Supplementary data to this article can be found online at https://doi. org/10.1016/j.scitotenv.2020.144895.

\section{References}

Abbas, Q., Yousaf, B., Ali, M.U., Munir, M.A.M., El-Naggar, A., Rinklebe, J., Naushad, M., 2020. Transformation pathways and fate of engineered nanoparticles (ENPs) in distinct interactive environmental compartments: a review. Environ. Int. 138, 105646.

Abdel Latef, A.A.H., Srivastava, A.K., El-sadek, M.S.A., Kordrostami, M., Tran, L.S.P., 2018. Titanium dioxide nanoparticles improve growth and enhance tolerance of broad bean plants under saline soil conditions. Land Degrad. Dev. 29, 1065-1073.

Allison, S.D., Martiny, J.B., 2008. Resistance, resilience, and redundancy in microbial communities. P. Natl. Acad. Sci. USA 105, 11512-11519.

Antisari, L.V., Carbone, S., Gatti, A., Vianello, G., Nannipieri, P., 2013. Toxicity of metal oxide $\left(\mathrm{CeO}_{2}, \mathrm{Fe}_{3} \mathrm{O}_{4}, \mathrm{SnO}_{2}\right)$ engineered nanoparticles on soil microbial biomass and their distribution in soil. Soil Biol. Biochem. 60, 87-94.

Bolyen, E., Rideout, J.R., Dillon, M.R., Bokulich, N.A., Abnet, C.C., Al-Ghalith, G.A., Alexander, H., Alm, E.J., Arumugam, M., Asnicar, F., 2019. Reproducible, interactive, scalable and extensible microbiome data science using QIIME 2. Nat. Biotechnol. 37, 852-857. 
Cai, L., Tong, M., Wang, X., Kim, H., 2014. Influence of clay particles on the transport and retention of titanium dioxide nanoparticles in quartz sand. Environ. Sci. Technol. 48, 7323-7332.

Cardman, Z., Arnosti, C., Durbin, A., Ziervogel, K., Cox, C., Steen, D., Teske, A., 2014. Verrucomicrobia are candidates for polysaccharide-degrading bacterioplankton in an arctic fjord of Svalbard. Appl. Environ. Microbiol. 80, 3749-3756.

Chen, G., Liu, X., Su, C., 2011. Transport and retention of $\mathrm{TiO}_{2}$ rutile nanoparticles in saturated porous media under low-ionic-strength conditions: measurements and mechanisms. Langmuir 27, 5393-5402.

Colatriano, D., Tran, P.Q., Guéguen, C., Williams, W.J., Lovejoy, C., Walsh, D.A., 2018. Genomic evidence for the degradation of terrestrial organic matter by pelagic Arctic Ocean Chloroflexi bacteria. Commun. Biol. 1, 90.

Colman, B.P., Wang, S.-Y., Auffan, M., Wiesner, M.R., Bernhardt, E.S., 2012. Antimicrobial effects of commercial silver nanoparticles are attenuated in natural streamwater and sediment. Ecotoxicology 21, 1867-1877.

Ernst, R., Ejsing, C.S., Antonny, B., 2016. Homeoviscous adaptation and the regulation of membrane lipids. J. Mol. Biol. 428, 4776-4791.

Falkowski, P.G., Fenchel, T., Delong, E.F., 2008. The microbial engines that drive Earth's biogeochemical cycles. Science 320, 1034-1039.

Fan, W., Peng, R., Li, X., Ren, J., Liu, T., Wang, X., 2016. Effect of titanium dioxide nanoparticles on copper toxicity to Daphnia magna in water: role of organic matter. Water Res. 105, 129-137.

Fang, J., Shan, X.-Q., Wen, B., Lin, J.-M., Owens, G., 2009. Stability of titania nanoparticles in soil suspensions and transport in saturated homogeneous soil columns. Environ. Pollut. 157, 1101-1109.

Ge, Y., Schimel, J.P., Holden, P.A., 2011. Evidence for negative effects of $\mathrm{TiO}_{2}$ and $\mathrm{ZnO}$ nanoparticles on soil bacterial communities. Environ. Sci. Technol. 45, 1659-1664.

Ge, Y., Schimel, J.P., Holden, P.A., 2012. Identification of soil bacteria susceptible to $\mathrm{TiO}_{2}$ and $\mathrm{ZnO}$ nanoparticles. Appl. Environ. Microbiol. 78, 6749-6758.

Gottschalk, F., Sonderer, T., Scholz, R.W., Nowack, B., 2009. Modeled environmental concentrations of engineered nanomaterials $\left(\mathrm{TiO}_{2}, \mathrm{ZnO}, \mathrm{Ag}\right.$, CNT, fullerenes) for different regions. Environ. Sci. Technol. 43, 9216-9222.

Griffiths, B.S., Philippot, L., 2013. Insights into the resistance and resilience of the soil microbial community. FEMS Microbiol. Rev. 37, 112-129.

Gupta, G.S., Senapati, V.A., Dhawan, A., Shanker, R., 2017. Heteroagglomeration of zinc oxide nanoparticles with clay mineral modulates the bioavailability and toxicity of nanoparticle in Tetrahymena pyriformis. J. Colloid Interface Sci. 495, 9-18.

Jacobsen, N.R., Pojano, G., Wallin, H.Jensen, 2010. Nanomaterial dispersion protocol for toxicological studies in ENPRA. Internal ENPRA report. March 2010. National Research Centre for the Working Environment, $8 \mathrm{pp}$.

Joshi, N., Ngwenya, B.T., French, C.E., 2012. Enhanced resistance to nanoparticle toxicity is conferred by overproduction of extracellular polymeric substances. J. Hazard. Mater. 241, 363-370.

Labille, J., Harns, C., Bottero, J.-Y., Brant, J., 2015. Heteroaggregation of titanium dioxide nanoparticles with natural clay colloids. Environ. Sci. Technol. 49, 6608-6616.

Langille, M.G., Zaneveld, J., Caporaso, J.G., McDonald, D., Knights, D., Reyes, J.A., Clemente, J.C., Burkepile, D.E., Thurber, R.L.V., Knight, R., 2013. Predictive functional profiling of microbial communities using 16S rRNA marker gene sequences. Nat. Biotechnol. 31, 814.

Li, D., Cui, F., Zhao, Z., Liu, D., Xu, Y., Li, H., Yang, X. 2014. The impact of titanium dioxide nanoparticles on biological nitrogen removal from wastewater and bacterial community shifts in activated sludge. Biodegradation 25, 167-177.

Li, M., Jain, S., Dick, G.J., 2016a. Genomic and transcriptomic resolution of organic matter utilization of deep-sea bacteria in Guaymas Basin hydrothermal plumes. Front. Microbial. 7, 1125

Li, S., Ma, H., Wallis, L.K., Etterson, M.A., Riley, B., Hoff, D.J., Diamond, S.A., 2016b. Impact of natural organic matter on particle behavior and phototoxicity of titanium dioxide nanoparticles. Sci. Total Environ. 542, 324-333.

Liu, G., Tao, Y., Zhang, Y., Lut, M., Knibbe, W.-J., van der Wielen, P., Liu, W., Medema, G., van der Meer, W., 2017. Hotspots for selected metal elements and microbes accumulation and the corresponding water quality deterioration potential in an unchlorinated drinking water distribution system. Water Res. 124, 435-445.

Liu, J., Tang, J., Wan, J., Wu, C., Graham, B., Kerr, P.G., Wu, Y., 2019. Functional sustainability of periphytic biofilms in organic matter and $\mathrm{Cu}^{2+}$ removal during prolonged exposure to $\mathrm{TiO}_{2}$ nanoparticles. J. Hazard. Mater. 370, 4-12.

McGee, C., Storey, S., Clipson, N., Doyle, E., 2017. Soil microbial community responses to contamination with silver, aluminium oxide and silicon dioxide nanoparticles. Ecotoxicology 26, 449-458.

McKee, M.S., Filser, J., 2016. Impacts of metal-based engineered nanomaterials on soil communities. Environ. Sci. Nano 3, 506-533.
Moll, J., Klingenfuss, F., Widmer, F., Gogos, A., Bucheli, T.D., Hartmann, M., van der Heijden, M.G., 2017. Effects of titanium dioxide nanoparticles on soil microbial communities and wheat biomass. Soil Biol. Biochem. 111, 85-93.

Moore, J.D., Stegemeier, J.P., Bibby, K., Marinakos, S.M., Lowry, G.V., Gregory, K.B., 2016 Impacts of pristine and transformed $\mathrm{Ag}$ and cu engineered nanomaterials on surficial sediment microbial communities appear short-lived. Environ. Sci. Technol. 50, 2641-2651.

Rana, A., Yadav, K., Jagadevan, S., 2020. A comprehensive review on green synthesis of nature-inspired metal nanoparticles: mechanism, application and toxicity. J. Clean. Prod. 122880.

Rosenfeld, J.S., 2002. Functional redundancy in ecology and conservation. Oikos 98, $156-162$.

Sheng, Z., Van Nostrand, J.D., Zhou, J., Liu, Y., 2015. The effects of silver nanoparticles on intact wastewater biofilms. Front. Microbiol. 6, 680.

Simon-Deckers, A., Loo, S., Mayne-L'hermite, M., Herlin-Boime, N., Menguy, N., Reynaud, C., Gouget, B., Carriere, M., 2009. Size-, composition-and shape-dependent toxicological impact of metal oxide nanoparticles and carbon nanotubes toward bacteria. Environ. Sci. Technol. 43, 8423-8429.

Simonin, M., Richaume, A., 2015. Impact of engineered nanoparticles on the activity, abundance, and diversity of soil microbial communities: a review. Environ. Sci. Pollut. R. 22, 13710-13723.

Simonin, M., Guyonnet, J.P., Martins, J.M. Ginot, M., Richaume, A, 2015. Influence of soil properties on the toxicity of $\mathrm{TiO}_{2}$ nanoparticles on carbon mineralization and bacterial abundance. J. Hazard. Mater. 283, 529-535.

Simonin, M., Richaume, A., Guyonnet, J.P., Dubost, A., Martins, J.M., Pommier, T., 2016. Titanium dioxide nanoparticles strongly impact soil microbial function by affecting archaeal nitrifiers. Sci. Rep. 6, 1-10.

Strickland, M.S., Lauber, C., Fierer, N., Bradford, M.A., 2009. Testing the functional significance of microbial community composition. Ecology 90, 441-451.

Su, Y., Wu, D., Xia, H., Zhang, C., Shi, J., Wilkinson, K., Xie, B., 2019. Metallic nanoparticles induced antibiotic resistance genes attenuation of leachate culturable microbiota: the combined roles of growth inhibition, ion dissolution and oxidative stress. Environ. Int. 128, 407-416.

Sun, T.Y., Gottschalk, F., Hungerbühler, K., Nowack, B., 2014. Comprehensive probabilistic modelling of environmental emissions of engineered nanomaterials. Environ. Pollut. 185, 69-76.

Tan, W., Peralta-Videa, J.R., Gardea-Torresdey, J.L., 2018. Interaction of titanium dioxide nanoparticles with soil components and plants: current knowledge and future research needs-a critical review. Environ. Sci. Nano 5, 257-278.

Thio, B.J.R., Zhou, D., Keller, A.A., 2011. Influence of natural organic matter on the aggregation and deposition of titanium dioxide nanoparticles. J. Hazard. Mater. 189, 556-563.

Tourinho, P.S., Van Gestel, C.A. Lofts, S., Svendsen, C., Soares, A.M., Loureiro, S., 2012 Metal-based nanoparticles in soil: fate, behavior, and effects on soil invertebrates. Environ. Toxicol. Chem. 31, 1679-1692.

Von Mersi, W., Schinner, F., 1991. An improved and accurate method for determining the dehydrogenase activity of soils with iodonitrotetrazolium chloride. Biol. Fertil. Soils 11, 216-220.

Wang, Z., Zhang, L., Zhao, J., Xing, B., 2016. Environmental processes and toxicity of metallic nanoparticles in aquatic systems as affected by natural organic matter. Environ. Sci. Nano 3, 240-255.

Wu, J., Zhan, M., Chang, Y., Su, Q., Yu, R., 2018. Adaption and recovery of Nitrosomonas europaea to chronic $\mathrm{TiO}_{2}$ nanoparticle exposure. Water Res. 147, 429-439.

Zhai, Y., Hunting, E.R., Liu, G., Baas, E., Peijnenburg, W.J., Vijver, M.G., 2019a. Compositional alterations in soil bacterial communities exposed to $\mathrm{TiO}_{2}$ nanoparticles are not reflected in functional impacts. Environ. Res. 178, 108713.

Zhai, Y., Liu, G., Bosker, T., Baas, E., Peijnenburg, W.J., Vijver, M.G., 2019b. Compositional and predicted functional dynamics of soil bacterial community in response to single pulse and repeated dosing of titanium dioxide nanoparticles. NanoImpact 16, 100187.

Zhang, R., Zhang, H., Tu, C., Hu, X., Li, L., Luo, Y., Christie, P., 2015. Facilitated transport of titanium dioxide nanoparticles by humic substances in saturated porous media under acidic conditions. J. Nanopart. Res. 17, 165.

Zhao, Y., Zhou, W., Wang, Y., Gao, B., Xu, X., Zhao, Y., 2020. The effect of humic acid and bovine serum albumin on the adsorption and stability of $\mathrm{ZnO}$ nanoparticles on powdered activated carbon. J. Clean. Prod. 251, 119695. 